\title{
EDUCAÇÃO, MEDICINA E RACIALIZAÇÃO NAS AULAS DE EDUCACÃO FÍSICA DAS ESCOLAS PRIMÁRIAS (PERNAMBUCO, DÉCADA DE 1930)
}

\author{
DOI: http://dx.doi.org/10.1590/2236-3459/67595
}

\author{
Adlene Silva Arantes \\ Universidade de Pernambuco (UPE), Nazaré da Mata/Pernambuco, Brasil
}

$\cos 80$

\begin{abstract}
Resumo
O estudo busca compreender como se davam as ações médicas para determinar o biotipo das crianças que frequentavam as aulas de educação física nas escolas primárias pernambucanas, na década de 1930, com vistas a perceber como se estabeleceram comparações entre brancos e negros, a partir das práticas de racialização presentes no ambiente escolar. Analisamos documentos da instrução pública, jornais de grupos escolares, revistas de ensino e da área médica, entre outros. Baseamos-nos no conceito de representação social de Roger Chartier (1990), em estudos sobre o pensamento racial brasileiro e da história da educação no Brasil. Destacamos o papel que teve a educação física no cenário nacional e local, tendo em vista que as políticas de racialização, baseadas em testes e medições antropométricas, imprimiram a missão de revigorar a raça e garantir o estabelecimento de uma sociedade saudável fisicamente, intelectualmente e moralmente. Palavras-chave: história da educação, medicina, racialização, escolas primárias.
\end{abstract}

\section{EDUCATION, MEDICINE AND RACIALIZATION IN CLASSROOMS OF PHYSICAL EDUCATION OF PRIMARY SCHOOLS (PERNAMBUCO, DECADE OF 1930)}

\begin{abstract}
The study seeks to understand how medical actions were taken to determine the biotype of children attending physical education classes in Pernambuco primary schools in the 1930s, in order to understand how comparisons were established between whites and blacks, based on practices of racialization present in the school environment. We analyzed documents of the public instruction, newspapers of school groups, magazines of teaching and of the medical area, among others. We are based on the concept of social representation of Roger Chartier (1990), in studies on Brazilian racial thought and the history of education in Brazil. We emphasize the role played by physical education in the national and local scenario, considering that racialization policies, based on anthropometric tests and measurements, have the mission of invigorating the race and ensuring the establishment of a healthy society physically, intellectually and morally.

Keywords: history of education, medicine, racialization, primary school.
\end{abstract}

\section{EDUCACIÓN, MEDICINA Y RACIALIZACIÓN EN LAS CLASES DE EDUCACIÓN FÍSICA DE LAS ESCUELAS PRIMARIAS (PERNAMBUCO, DÉCADA DE 1930)}

\section{Resumen}

El estudio busca comprender cómo se daban las acciones médicas para determinar el biotipo de los niños que frecuentaban las clases de educación física en las escuelas primarias pernambucanas, en la década de 
1930, con vistas a percibir cómo se establecieron comparaciones entre blancos y negros, a partir de las prácticas de racialización presentes en el ambiente escolar. Analizamos documentos de la instrucción pública, periódicos de grupos escolares, revistas de enseñanza y del área médica, entre otros. Se basan en el concepto de representación social de Roger Chartier (1990), en estudios sobre el pensamiento racial brasileño y la historia de la educación en Brasil. Destacamos el papel que tuvo la educación física en el escenario nacional y local, teniendo en cuenta que las políticas de racialización, basadas en pruebas y mediciones antropométricas, imprimieron la misión de revigorizar la raza y garantizar el establecimiento de una sociedad sana físicamente, intelectualmente y moralmente.

Palabras clave: historia de la educación, medicina, racialización, escuelas primarias.

\section{ÉDUCATION, MÉDECINE ET RACIALISATION EN CLASSE D'ÉDUCATION PHYSIQUE DES ÉCOLES PRIMAIRES (PERNAMBUCO, DÉCENNIE DE 1930)}

\section{Résumé}

L'étude cherche à comprendre comment donner des actions médicales pour déterminer le biotype des enfants qui suivent des cours d'éducation physique dans Pernambuco groupes scolaires dans les années 1930, afin de comprendre comment mettre en place des comparaisons entre les Blancs et les Noirs des pratiques actuelles de racialisation environnement scolaire. Nous analysons les documents d'éducation du public, des groupes de journaux scolaires, magazines scolaires et médicaux, entre autres. Nous basons sur le concept de représentation sociale de Roger Chartier, dans les études de la pensée raciale brésilienne et de l'histoire de l'éducation au Brésil. Nous soulignons le rôle qui avait l'éducation physique au scénario national et local étant donné que les essais politiques de racialisation fondées et des mesures anthropométriques imprimés mission de revigorer la race et de veiller à la mise en place d'une société saine physiquement, intellectuellement et moralement.

Mots-clés: histoire de l'éducation, médecine, racialisation, écoles primaires. 


\section{Introdução}

$\mathrm{N}$ este texto, que é parte de uma pesquisa mais ampla, buscamos compreender como se davam as ações médicas para determinar o biotipo ${ }^{1}$ das crianças que frequentavam as aulas de educação física nas escolas primárias pernambucanas na década de 1930, com vistas a perceber como se estabeleceram comparações entre brancos e negros, a partir das práticas de racialização presentes no ambiente escolar. Utilizamos como fontes documentos da instrução pública como programas de ensino das escolas primárias e relatórios. Além de jornais de grupos escolares, revistas de ensino, da área médica, entre outros. Baseamos-nos no conceito de representação social de Roger Chartier (1990) e em estudos sobre o pensamento racial brasileiro e sobre história da educação no Brasil.

Vale ressaltar que o discurso médico exercia forte influência na educação do período estudado ditando as regras para possibilitar o desenvolvimento de crianças saudáveis e, consequentemente, a regeneração da nação brasileira. Este discurso pode ser percebido tanto a partir das questões de higiene quanto das eugênicas, sobretudo considerando as primeiras décadas do século XX, no Brasil. Tratava-se de um discurso que se traduzia em processos de mensuração das condições físicas e mentais dos alunos e das condições de sua educação. Como parte desses processos destacamos a realização de testes de medidas antropométricas como: o índice ponderal, o índice de robustez, a capacidade vital e o perímetro torácico, etc.

Todo o procedimento de medidas psicológicas, físicas ou biológicas visava classificar as crianças para favorecer a criação de possíveis classes homogêneas. Assim propiciava-se, através de critérios "científicos", a seleção e o agrupamento de crianças que estariam em um mesmo nível morfofisiológico, com o pretexto de facilitar a aprendizagem.

Nesse contexto, a educação física foi instituída nas escolas como um instrumento de controle da regeneração social, passando assim a desempenhar um papel fundamental nos processos de racialização e ao mesmo tempo de higienização da sociedade.

Estamos utilizando o termo racialização referindo-se ao "processo ideológico e político por meio do qual determinadas populações eram identificadas pela referência às suas características fenotípicas (reais ou imaginárias), de tal modo que só pudessem ser compreendidas como tendo uma possível unidade biológica". (KAERCHER, 2005, p. 100). Portanto, o conceito de racialização não é neutro. Ele é sistêmico por operar metódica e intencionalmente com objetivos bem definidos. É polissêmico porque se implementa a partir de múltiplos sentidos discursivos e, é multidirecional ao dirigir-se a todos os sujeitos independentemente de gênero, nacionalidade, classe, pertencimento étnico, etc. A racialização pode ser pensada, portanto, como uma pedagogia. (KAERCHER, 2010, p. 85).

Em relação à eugenia, podemos dizer que no período estudado esteve mais presente o que Stepan (2005, p. 94) chamou de eugenia preventiva, isto é, aquela que propalava a erradicação dos venenos raciais e das doenças venéreas. A autora identificou em seu estudo a Eugenia Positiva que incentivava a reprodução dos adequados e a Eugenia Negativa que controlava a reprodução dos inadequados. (STEPAN, 2005, p. 94).

\footnotetext{
1 A partir das várias quantificações corporais (traços físicos e craniométricos), que por vezes recebiam tratamentos matemáticos e estatísticos, foram desenvolvidas as classificações das características corporais dos indivíduos. Esse modo de caracterização era, então, denominado pelos biotipologistas como 'biotipo'. (VIMIEIRO-GOMES, 2012, p. 707).
} 
No que se refere à educação física no Brasil, podemos dizer que esta passou por períodos distintos. Até os anos de 1930 tivemos uma Educação Física prioritariamente pautada no higienismo, preocupada com o saneamento público, a prevenção de doenças e uma sociedade livre de vícios. Após o referido período, especialmente nos anos de 1940, em plena vigência do Estado Novo, uma Educação Física de concepção militarista, com o intuito de formar uma juventude pronta para defender a Pátria. (GHIRALDELLI JR., 1994, p. 16-17). No período por nós estudado encontramos elementos das concepções higienista e militarista.

A concepção higienista enfatizava a questão da saúde em primeiro plano. Assim, o papel da Educação Física era formar homens e mulheres sadios, fortes, dispostos à ação. Mais do que isso, informa o autor, que a educação física higienista não se responsabilizava somente pela saúde individual das pessoas, mas agiu como protagonista num projeto de "assepsia social". Assim, para tal concepção, a ginástica, o desporto, os jogos recreativos, etc. devem, antes de qualquer coisa, disciplinar os hábitos das pessoas no sentido de leválas a se afastarem de práticas capazes de provocar a deterioração da saúde e da moral, o que comprometia a vida coletiva. "Baseava-se principalmente no conhecimento científico e biológico, que buscava melhorar as condições de vida da população por meio do controle do comportamento com vistas à saúde pública." (GHIRALDELLI JR., 1994, p. 16).

A concepção de Educação física militarista tinha como objetivo fundamental a obtenção de uma juventude capaz de suportar o combate, a luta, a guerra. Assim, a educação física deveria ser suficientemente rígida para elevar a nação à condição de "servidora e defensora da pátria", funcionando como selecionadora de "elites condutoras", capazes de distribuir melhor os homens e as mulheres nas atividades sociais e profissionais. Portanto, o papel da educação física era o de "colaboração no processo de seleção natural", eliminando os fracos e premiando os fortes, no sentido da "depuração da raça." (GHIRALDELLI JR.,1994, p. 18). A ideia central dessa concepção, segundo o autor, era o "aperfeiçoamento da raça", seguindo assim as determinações impostas pelas falsas conclusões encetadas pela biologia nazifacista. Daí a educação física funcionar como atividade "aceleradora do processo de seleção natural." (GHIRALDELLI JR., 1994, p. 26).

Ao longo do texto, abordaremos os discursos médicos voltados para a educação física nas aulas de ensino primário em grupos escolares e as práticas antropométricas para estabelecer a biotipologia ${ }^{2}$ do escolar pernambucano nesses espaços educativos.

\section{O discurso médico na educação física pernambucana}

Entendemos discursos como sinônimo de representações tal como concebe Chartier (1990), ou seja, como discursos que apreendem e estruturam o mundo, permitindo assim, compreender a relação entre os discursos e as práticas. Consideramos, portanto, que as lutas de representações têm tanta importância como às lutas econômicas para compreender os mecanismos pelos quais um grupo impõe, ou tenta impor, a sua concepção do mundo social, os valores que são os seus, e o seu domínio.

Segundo Gondra (2003), o debate sobre a higiene no âmbito educacional teve

\footnotetext{
${ }^{2}$ Biotipologia foi o termo criado, nos anos 20, pelo médico italiano Nicola Pende (1880-1970) para caracterizar a "ciência das constituições, temperamentos e caracteres". A biotipologia representaria "a fase científica das doutrinas constitucionalistas" (estudo dos temperamentos), num enlaçamento da ciência experimental com o estudo da constituição humana. (VIMIEIRO-GOMES, 2012, p. 712).
} 
inserção na sociedade pelo campo médico já no século XIX, quando estes almejavam a disseminação de suas ideias para outras áreas de atuação profissional, como, por exemplo, entre os professores que atuavam decisivamente nos espaços de escolarização da sociedade. Assim, ao se referir ao Município da Corte, o autor menciona que:

\begin{abstract}
A medicina deveria penetrar na sociedade, incorporando o meio urbano como alvo de sua reflexão e de sua prática, e o de que deveria constituir com o apoio indispensável ao exercício de poder por parte do Estado [...] na expansão da medicina, a escola não é esquecida numa educação de um modo mais geral, pois, para formar as novas gerações seria necessária uma intervenção não apenas no espaço público da escola, mas, também no espaço privado da casa. (GONDRA, 2003, p. 525).
\end{abstract}

Nesse contexto, a medicina encontrou na escola um novo espaço para se ocupar dos corpos. Para isso utilizava-se dos argumentos científicos que recobriam um amplo espectro de questões vinculadas à escola, tais como o problema da localização dos edifícios escolares, da necessidade de uma edificação própria e apropriada para funcionar como escola, do ingresso dos alunos, do tempo e dos saberes escolares, da alimentação, do sono, do banho, das roupas, dos recreios, da ginástica, das percepções, da inteligência, da moral e, inclusive, das excreções corporais. (GONDRA, 2003).

No Estado de Pernambuco, a partir de 1930, atrelado à educação física e, consequentemente, à preocupação com a saúde dos escolares, o fator racial apareceu como um problema para o futuro da pátria. É o que pode ser observado, por exemplo, no relatório apresentado ao Interventor Federal pelo responsável pela Diretoria de Higiene, Waldemir Miranda ${ }^{3}$, em 20 de dezembro daquele ano. O relator inicia seu texto elogiando o governador, em exercício na época, pelo seu gesto patriótico de interesse pela saúde dos escolares em um país em que a criança até pouco tempo vivia em completo abandono. Indaga: "Que seria da pátria de amanhã sem o preparo da raça pela assistência à infância?" Responde em seguida:

\begin{abstract}
Nossa incúria nesse particular imporia no enfraquecimento das forças vitaes da nação pela decadência physica da raça cujo sangue já vem sendo intoxicado há longos annos pela Constancia de malles sociaes que nos afflingem sem despertar reação prophylactica por parte dos governos passados. Raça nova, amparada pela prodigalidade da natureza, começava a decahir sob o peso de uma hereditariedade pathologica que somente a hygiene seria capaz de corrigir. De facto, já se disse que a hygiene era a rainda da nossa epocha. Rainha ou Fada deve ser conhecida de todos para melhor influir na formação pshycho-somatica das novas gerações ${ }^{4}$. (MIRANDA, 1930, p. 1-3, grifos meus).
\end{abstract}

Analisando o trecho acima percebemos que Waldemir Miranda se referia à mistura racial como um fator de enfraquecimento da raça e à decadência física por causa do sangue negro que intoxicou a nação. Esse eugenista da corrente de eugenia preventiva queria desintoxicar o sangue do brasileiro e revigorar a raça como tantos o queriam naquele momento histórico. Para que isso acontecesse, segundo ele, deveríamos cercar a saúde

\footnotetext{
${ }^{3}$ Médico, professor e ensaísta brasileiro, fundador e primeiro diretor da Faculdade de Ciências Médicas de Pernambuco (1950-1956), era sócio honorário da Sociedade Brasileira de Médicos Escritores, Regional de Pernambuco. Disponível em: <https://pt.wikipedia.org/wiki/Waldemir_Soares_de_Miranda>. Acesso em: 29 fev. 2016.

${ }^{4}$ Ressaltamos que mantivemos a grafia original das fontes com as quais trabalhamos.
} 
da criança, especialmente dos escolares, permanecendo os órgãos estatais em vigilância. Deveriam, ainda, manterem-se em constante observação, porque a evolução e as modificações que sofrem os organismos infantis são constantes, o que os torna mais aptos a contraírem as doenças epidêmicas.

\begin{abstract}
Por tudo isso e por outras razões de sobejo conhecidas impõe-se a necessidade da inspeção medica das escolas não é uma inovação para fornecer empregos agradáveis a novos doutores. Pelo contrario, cabe ao serviço medico-escolar resolver dos destinos da raça, velando a cultura das novas gerações sob o tríplice aspecto do desenvolvimento physico, espiritual e moral. (MIRANDA, 1930, p. 4, grifos meus).
\end{abstract}

Portanto, o serviço médico escolar tinha a responsabilidade de solucionar os problemas da raça para que as novas gerações tivessem um desenvolvimentos adequado fisicamente, espiritualmente e moralmente. Incentivavando-se assim, a Eugenia Positiva e a Eugenia Negativa ao mesmo tempo.

Ainda na década de 1930 é possível perceber também algumas medidas do governo para orientar a educação física para que ela se enquadrasse nos "moldes rigorosamente scientificos". (PERNAMBUCO, 1931, p. 9). Nesse momento, se adotava o método francês ${ }^{5}$ de educação física, oficializado e melhorado no Brasil. A justificativa para essa preocupação era explicada da seguinte forma:

[...] Mas do que em qualquer outro povo, talvez, é inadiavel cogitar seriamente entre nós da base physica da raça. Si na grande Republica do Norte, a saude, a capacidade physica da nação, consideram-se a base de todo o progresso social, muito maior attenção reclama a educação physica no Brasil, onde causas antihygienicas accumuladas crearam uma raça enfermiça, que é mister a todo custo resgatar. (PERNAMBUCO, 1931, p. 9, grifos meus).

O preparo de professoras especializadas acontecia em um curso regular que as formava com aulas teóricas e práticas de exercícios físicos, regidas pelo Instrutor Geral. As candidatas recebiam princípios de anatomia e fisiologia aplicadas à educação física, fisiologia da fadiga, higiene do esforço, biometria pedagógica, lecionados por médicos inspetores do serviço. As crianças eram reunidas para os exercícios, não em classes escolares, mas em turmas homogêneas, segundo a idade anatomo-fisiológica, havendo ainda turmas especiais de ginástica corretiva e ginástica respiratória para débeis e anormais. Portanto,

\footnotetext{
${ }^{5}$ Elaborado na década de 1920 na Escola Militar de Joinville-le-Pont (Paris) sendo aprovado pelos Ministérios da Guerra e da Instrução Pública em 1927. Sua tradução foi oficializada no Brasil em 1931 sob o título de Regulamento o 7 de Educação Física ou Método Francês, cuja centralidade recaia na ideia de que a Educação Física deveria orientar-se a partir de princípios anátomo-fisiológicos abrangendo, para tanto, os seguintes ciclos: Educação Física elementar (pré-pubertária) de 4 a 13 anos; Educação Física secundária (pubertária e pós-pubertária) de 13 a 18 anos; Educação Física superior (desportiva e atlética); Educação Física feminina; o objetivo de fortalecer a saúde, a força, a resistência, a destreza, a têmpera de caráter e a harmonia das formas. Para tanto indicava o uso de seis formas de trabalho: os jogos, os assouplissements (flexionamentos), os exercícios educativos, os desportos individuais e os desportos coletivos, cujas regras a seguir eram o agrupamento dos indivíduos, a adaptação e atração do exercício e a verificação periódica da instrução. Além destas prescrições, o Regulamento apresentava, ainda, recomendações higiênicas voltadas para o robustecimento da população. Disponível em: <http://cev.org.br/etc/regulamento/fla01.htm>. Acesso em: 29 fev. 2016.
} 
Cada alumno é objecto de um estudo clinico e biometrico completo, sobre o qual se baseia a ficha individual de educação physica, sendo os exames medicos renovados periodicamente, para a constatação de resultados colhidos com a pratica dos exercicios physicos. (PERNAMBUCO, 1931, p. 10).

Vale ressaltar que esses exames eram compostos por testes psicológicos e antropométricos cujos resultados eram racializados, isto é, havia a separação dos resultados das crianças negras em comparação com as crianças brancas. Para isso, utilizava-se a classificação de Roquette-Pinto ${ }^{6}$.

Naquele período, em Pernambuco, também foram adaptadas áreas específicas para a prática da educação física, tais como: pistas de corrida, campos de ginástica e jogos, instalações para exercícios e recreios segundo a orientação mais moderna, em todos os grupos escolares. Essa organização deveria culminar no Parque de Educação Física cuja construção era amplamente pregada pelo Governo, em vasta área central da cidade, onde as crianças de todas as escolas encontrariam instalações completas para jogos e exercícios, base da saúde e do vigor das novas gerações. Portanto, em Pernambuco, as concepções higienista e militarista de educação física estavam presentes simultaneamente.

Vale resaltar que havia uma orientação geral para que os exercícios físicos fossem praticados ao ar livre, em áreas que foram "immédiatamente adaptadas para esse fim e, durante o mau tempo, em pavilhões e outros logares abrigados, com sufficiente arejamento e condições geraes de perfeita hygiene." (PERNAMBUCO, 1931, p. 109). Abaixo, seguem algumas determinações/orientações para a realização dos exercícios:

- Os exercicios serão dirigidos pelas monitoras, sob a orientação geral do professor de educação physica e a vigilancia frequente dos medicos Inspectores, que procurarão adaptar os exercicios ás condições individuaes da creança, creando turmas para gymnastica corretiva nos casos de deformações, asymetrias, gymnastica hygienica, respiratoria para os debeis e de reeducação motora para os anormaes.

- Nos exercicios destinados ás meninas, serão tomadas em consideração a physiologia especial e a esthetica de forma e do movimento dos organismos a que elles se destinam.

- Durante os exercicios, usarão as creanças vestes convenientes, amplas e simples e calçados de sola flexivel, segundo o modelo indicado pelo Inspector. (PERNAMBUCO, 1931, p. 109).

Caberia às monitoras de educação física organizar fichas individuaes dos escolares, segundo o modelo adotado, nas quais eram registradas as condições anatômicas e fisiológicas, bem como os resultados individuais revelados pelos exames médicos e antropométricos realizados em períodos regulares, no decorrer no ano letivo. Assim, todos esses procedimentos faziam parte constitutiva da cultura escolar e deveriam contribuir para a formação do aluno em cidadão, nesse lugar onde se procurou reformar a carne: a escola foi pensada como lugar para "reabilitar corpos". (VAGO, 2002). Em Pernambuco, nesse contexto,

\footnotetext{
${ }^{6}$ Edgar Roquette-Pinto foi médico legista, professor, antropólogo, etnólogo analisando a classificação racial e o processo "combinatório" de nossa miscigenação com o objetivo de conhecer as características dos "tipos antropológicos" dos brasilianos(termo utilizado por ele para se referir aos brasileiros) identificou quatro grandes grupos, de acordo com denominações extraídas do grego, as quais chamou de leucodermos (brancos), faiodermos (brancos $x$ negros), xantodermos (brancos $x$ indios) e melanodermos (negros) baseando-se nos atributos de cor/raça ligados à noção biológica de raça, que levava em consideração a cor da pele, tonalidade dos olhos e características do cabelo. (SOUZA, 2008, p. 218).
} 
[...] serão as creanças submetidas aos exercicios physicos não por classes escolares, como actualmente, mas por grupos homogenos no ponto de vista da edade anatomo-physiologica, organisados de accordo com os dados colhidos em exame medico e anthropometrico, pelos medicos Inspectores com o auxilio das monitoras de educação physica. (PERNAMBUCO, 1931, p. 109).

Em 1932, o Diretor Técnico da Educação, Aníbal Bruno ${ }^{7}$, menciona uma ficha de educação física com dados médicos e biométricos que permitissem distribuir as crianças segundo os critérios acima mencionados. $O$ referido inspetor afirmou, em palestra proferida na Conferência de Educação, que procurava empregar todas as suas energias "pela grandeza da raça". Em seguida, se deteve a explicar a situação da educação física em Pernambuco. Iniciou abordando a necessidade da criação de uma Superintendência do Serviço de Saúde e Educação Física, lembrando que o Estado de Pernambuco não havia se afastado

[...] da ideia de que a Educação Física deve andar diretamente ligada a todos os serviços em prol da saúde do escolar, necessitando para tal de uma direção única, diretamente ligada e, consequentemente, subordinada ao Departamento dirigente da educação em geral. (GOMES, 1935, p. 19).

Para tanto, ressaltou ainda que estava "crente de que não vira longe o dia em que, ao lado da clínica, formara a educação física em plano paralelo como parte integrante de uma bem orientada medicina preventiva, a verdadeira medicina do futuro." (GOMES, 1935, p. 19).

Assim, ficava nítido o lugar da educação física no processo de articulação com a medicina para garantir o futuro da raça pernambucana, e, consequentemente, brasileira. A seguir abordaremos os tipos de medidas necessárias para estabelecer o biótipo dos alunos que frequentavam as escolas pernambucanas com o objetivo de facilitar a organização das classes escolares.

\section{Práticas antropométricas no espaço pernambucano}

Sabemos que a antropometria, desde o século XIX, era o método mobilizado pelas ciências da vida para precisar o lugar do homem na natureza, definir caracteres raciais e valores biossociológicos. Essas práticas eram baseadas em um pressuposto de cientificidade, para o qual a diversidade humana também obedecia a "condições precisas e leis fixas". Tal olhar da medicina constitucional sobre a individualidade teria deslocado o papel da categorização racial na conformação dos indivíduos. (VIMIEIRO-GOMES, 2012, p. 708-709).

No mesmo sentido, Schwarcz (1993, p. 96-97) afirma que a principal questão científica de fundo posta no curso da investigação era como proceder em face da heterogeneidade nas características biológicas e antropológicas da população brasileira.

\footnotetext{
${ }^{7}$ Bacharel em Ciências Jurídicas e Sociais pela Faculdade de Direito do Recife e em Ciências Médicas pela Faculdade de Medicina do Recife. Foi diretor do Departamento de Educação de Pernambuco no período de 1930 A 1935. Dedicou-se ao ensino de diversas disciplinas, sendo professor da Faculdade de Filosofia e Ciências Sociais de Pernambuco; da Escola de Aperfeiçoamento do Instituto de Educação de Pernambuco; da Escola Normal Pinto Júnior; da Faculdade de Medicina do Recife (livre docente); do Ginásio Pernambucano (livre docente); da Escola Normal Oficial do Estado e da Faculdade de Direito do Recife. (SELLARO, 2009).
} 
Essa heterogeneidade foi considerada, nos anos seguintes à publicação de O Normotypo Brasileiro, uma limitação no uso dos modelos da 'Escola Italiana' perante a realidade corpórea dos brasileiros, pois, enquanto na Itália haveria "um tipo de população definitivamente caldeado", no Brasil não existiria um "centro de população homogênea". Todavia, dizia ele, isso não impediria a busca do estabelecimento do normotipo brasileiro.

Uma das justificativas apontadas pelos médicos brasileiros para adotar a Escola Italiana de Biotipologia baseou-se em um suposto status de cientificidade, proveniente do trato com procedimentos de quantificação. Essa escola não seria baseada, "como outras", "na simples impressão inspectiva do indivíduo". Ela se serve "do método científico, antropométrico", para levantar os valores das medidas corporais, principalmente do tronco e dos membros, para a classificação biotipológica e, com isso, socorre-se "de meios estatísticos para a elaboração dos resultados e sua interpretação". (VIMIEIRO-GOMES, 2012, p. 711).

Em relação à prática antropométrica escolar, Waldemir Miranda, médico responsável pela Diretoria de Higiene de Pernambuco em 1931, informou como as monitoras de educação física deveriam preencher um instrumento que ele denominou de ficha de educação física para registro dos dados obtidos a partir das medições antropométricas e dos dados clínicos dos alunos. Nesse momento especifico no grupo Maciel Pinheiro, por exemplo, as turmas para os exercícios eram constituídas pelas "classes". Alunos de idades, sexos, estaturas, compleições diferentes, num mesmo bloco. A classificação se fazia pela idade fisiológica. Segundo Miranda, esta renovação de processo, colocando a educação física acima da intelectual e da moral, como exigiam as condições de capacidade vital, resistência, saúde, dos nossos escolares, devia-se a Aníbal Bruno, à frente da Diretoria Técnica da Educação. (PERNAMBUCO, 1931, p. 27).

Em seguida, o autor explica para as monitoras como elas deveriam preencher as fichas de educação física, que seriam baseadas em pesquisas antropométricas. O primeiro ponto a ser observado era a idade.

A referencia da idade é das mais importantes na confecção da nossa ficha de educação physica. Como veremos proximadamente, esse elemento conta verdadeiramente para a classificação dos escolares, mesmo aquella que abstrahe da idade chronologica para attender á physiologica. (MIRANDA, 1931, p. 28).

Outro elemento que se considerava no preenchimento da dita ficha era a estatura, ou seja, o comprimento do corpo humano, da planta dos pés ao vértice ou a distância vertical que separa dois planos horizontais, um sobre o qual repousa o indivíduo, outro que se apoia sobre o vértice da cabeça. E como essa medida era feita?

O objecto utilizado é a "craveira" (ou toeza) que se compõe de uma escala graduada vertical, em geral de 2 metros de extensão, erecta sobre um estrado - onde o escolar se perfila - e ao longo do qual corre uma peça horizontal - "haste" - que deve vir descançar sobre o vertice craneano. $O$ estrado deverá ser verificado com o nivel dagua; a escala, graduada em centimetros e millimetros (aferida a sua verticalidade com um prumo) e a haste, munida, posteriormente, de uma tarracha, ou parafuso de madeira, que a fixará sobre a escala, depois de constatada a estatura. (MIRANDA, 1931, p. 29).

Passemos então para a próxima medida, ou seja, o peso. Considerava-se o resultado das ações que a gravidade exerce sobre todos os pontos do corpo. O peso 
deveria ser tomado em balanças decimais, destinadas a pesar, especialmente, o organismo humano. Ressaltava-se que era preciso tomar cuidado com as balanças que se encontravam nos armazéns e vendas, utilizadas na pesagem de grandes volumes de mercadorias, pois estavam geralmente viciadas e nem sempre exprimiam frações menores de 500 gramas.

Por isso, a necessidade de aferir rigorosamente a balança de que nos vamos servir, para evitar possibilidades de erro. O processo de pesagem deveria ser feito da seguinte forma, depois de aferição cuidadosa, e colocada sobre piso plano,

O escolar submettido á pesagem deve achar-se descalço e despojado das pequenas peças do vestuario: palitós, aventaes, blusas, saiotes, suspensorios, cintos, etc. Nada é que se apresentem de tôrso nú, conservando os meninos a calça e as meninas a calçola. Não sendo possivel, por qualquer circumstancia, dispensar o escolar as varias peças do seu vestuario, devemos exigir-lhe, pelo menos, a retirada dos sapatos. Deve o escolar ser pesado pela manhã, duas horas antes do almoço, ou á tarde, tres horas depois desta refeição. (MIRANDA, 1931, p. 31).

O perímetro thoraxico também era um componente da ficha da educação física que correspondia à circunferência do tórax. Essa medida era verificada estabelecendo a diferença entre a inspiração e a expiração, o que representava o coeficiente de dilatação pulmonar. Assim, era a perimetria que dava a ideia da elasticidade torácica e dos benefícios que a esta trazia para os exercícios físicos. O objeto utilizado na prática da perimetria torácica era a fita métrica inextensível, graduada em centímetros, convenientemente encerrada, mas havia a possibilidade de colar-se á pele do escolar, comprometendo o resultado da pesquisa. O processo de medir o perímetro do tórax se dava da seguinte forma:

O perimetro thoraxico pode ser tomado a tres alturas differentes:

1.. - immediatamente abaixo da axilla - perimetro axillar;

2.. - sobre os mamillos - perimetro mamillar;

$3 .$. - ao nivel do appendice xiphoide - perimetro xiphodeu.

(MIRANDA, 1931, p. 32).

No caso das meninas o indicado era o Perímetro xiphoideu, que consistia em medir na mesma posição. Passava-se a fita cerca de quatro centímetros abaixo da aréola mamária, isto é, ao nível do apêndice xiphoideu. Daí o nome perímetro xiphodeu ou xiphoesternal ou, ainda, sub-peitoral. O autor informava que,

Em nosso serviço, na Directoria Technica de Educação, deliberamos a adoção uniforme do perimetro xiphoideu o qual, offerecendo dados utilissimos do desenvolvimento e da elasticidade thoraxicas, presta-se bem ás meninas, em quem o crescimento dos seios viria invalidar o perimetro mamillar. O perimetro xiphoideu concilia, assim, os dois sexos, num mesmo objectivo. Foi, aliás, o perimetro escolhido pela Commissão Internacional do XV Congresso de Anthropologia, reunido ha poucos annos: "um plano horizontal passando pela base do appendice xifoide [...]". (PERNAMBUCO, 1931, p. 33).

O perímetro abdominal também era uma medida que constava na ficha antropométrica. Para se obter a referida medida utilizava-se a fita métrica já referida, estando o indivíduo de pé. Ela deveria passar ao nível da cicatriz umbilical, comportandose o examinado naturalmente, isto é, sem qualquer contração dos músculos abdominais. 
O Diametro bi-acromial e o coeficiente de robustez são as últimas medidas que constam na ficha antropométrica. O diâmetro bi-acromial traduz a largura dos ombros. Era tomado com o compasso de espessura, grande modelo, escolhendo-se os dois pontos laterais extremos dos acrômios, que são saliências ósseas da parte superior e extrema das omoplatas.

Em relação ao coeficiente de robustez, o autor mencionava que as medidas não teriam valor quando examinados isoladamente, por isso, para se conhecer 0 desenvolvimento regular do sujeito, imaginaram-se fórmulas aritméticas, cujos resultados classificavam o indivíduo como valor orgânico. "São os indices ou coefficientes de robustez - "expressão do valor physiologico do individuo" ou "valor numerico do individuo". (MIRANDA, 1931, p. 37). Os índices de robustez davam a noção geral do desenvolvimento corporal do indivíduo, utilizando para isso os dados antropométricos e servindo de base á chamada classificação pela idade fisiológica.

Portanto, a partir da antropometria se estabelecia a biotipologia dos escolares de Pernambuco, ou seja, os índices citados eram utilizados em estudos e pesquisas realizados pelos médicos pernambucanos para se estabelecer o biotipo das crianças que frequentavam as escolas primárias, como veremos a seguir.

\section{O biotipo do escolar pernambucano}

Em artigo intitulado "Contribuição à antropometria do escolar recifense", de autoria dos médicos Gil de Campos e Armando Macedo, vinculados ao Serviço de Higiene Escolar do Departamento de Saúde Pública, publicado em 1934, encontramos uma discussão na qual os autores apontam que entre as diversas versões acerca da relação entre a inteligência do escolar e o seu desenvolvimento físico, dois nomes se destacaram, quais sejam: os médicos Porter e Binet, responsáveis pelos primeiros testes de QI, eram considerados pesquisadores importantes para os estudos antropométricos. O primeiro, responsável pela "trivialidade do aforismo latino ter se transformado em axioma". (CAMPOS; MACEDO, 1934, p. 125). E o segundo, por ter realizado acuradas experiências e ter concluído que existia base na relação entre o físico desenvolvido e o adiantamento intelectual.

\footnotetext{
Essa relação de dependencia se desmente entretanto em uma maioria tão flagrante que não poderia servir a um diagnostico individual. São suas palavras decisivas (Binet). Tal minoria, porém, nos leva na pratica a descobrir a fragilidade da ponte lançada entre a capacidade fisica e a capacidade intelectual. Os dados anatômicos e fisiologicos não nos autorizam afirmar com segurança o diagnostico pedagogico. (CAMPOS; MACEDO, 1934, p. 125, grifos meus).
}

A partir do trecho acima percebemos que é nítida a opinião dos médicos pernambucanos ao apontarem a inconsistência da relação entre capacidade física e capacidade intelectual. Apesar da existência de testes variados nada se tinha de concreto para apontar com segurança o diagnostico pedagógico dos escolares. Contudo, informaram ainda que algumas vezes se depararam com uma criança cuja miséria física se aliava a um estado intelectual retardado. Nesses casos eram examinados os dentes, o fundo da garganta, tubo digestivo, coração, pulmões, verificada a taxa de hemoglobina e encontravam a relação de causalidade. "E' quando, então, nos beneficiamos das vantagens da mensuração corporal, da antropometria que nos despertou a suspeita, logo confirmada." (CAMPOS; MACEDO, 1934, p. 125). Na sequencia, os autores apontaram a importância social 
desse processo de medições com foco nos alunos afirmando que:

O exame e a medida do desenvolvimento físico das crianças não têm somente um interesse de pedagogia; todas essas questões, quando bem compreendidas, ultrapassam os interesses próprios da escola e tomam uma verdadeira importância social, pois metem em jogo o futuro da raça e a organização da sociedade." (CAMPOS; MACEDO, 1934, p. 130-131, grifos meus).

Daí a necessidade que se propagava de articulação entre a escola e a sociedade, tão necessária para garantir o futuro da raça e a organização social tão almejada naquele momento especifico pelos médicos que atuavam nos espaços escolares. Nesse contexto, vale ressaltar que a pesquisa desenvolvida pelos referidos médicos sobre o índice antropométrico dos escolares do Recife, contou com 943 alunos dos Grupos Escolares João Barbalho, Joaquim Távora, Maciel Pinheiro e Siqueira Campos. Foram examinadas crianças entre 5 e 14 anos de idade. Nas suas palavras "utilizamos para obtenção das medidas corporais, da toesa de Dusfestel, balança, fita métrica, dinamômetro e espirômetro". (CAMPOS; MACEDO, 1934, p. 126).

Em 1935 foi elaborado um Plano para organização do Serviço de Educação Física no Estado, que foi levado a VII Conferência Nacional de Educação que aconteceu no Distrito Federal e apresentado pelo Inspetor de Educação Física e Professor da Escola de Aperfeiçoamento José de Oliveira Gomes. Segundo o referido inspetor,

Pernambuco, diga-se de passagem, muito já tem feito em beneficio da educação física de seus escolares. Esse muito, porém, é considerado mínimo, comparado ao que deverá fazer tão depressa quanto possível. O que até agora esta feito, nada mais representa do que as fundações que servirão de base ao grande arcabouço que permitirá a construção de uma nova raça. (GOMES, 1935, p. 18, grifos meus).

A partir desse plano se organizou no estado o Serviço de Antropologia e Medicina Escolar com o objetivo de levar a termo as pesquisas necessarias à determinação das condições fisicas e psiquicas dos escolares, e ainda para que orientasse uma obra esclarecida e eficiente de assistencia escolar, sob o ponto de vista alimentar e médico. Dentro desse serviço estava a secção de Morfo-Fisiologia, que, segundo seu inspetor, se achava perfeitamente aparelhada para as pesquisas referentes á Morfologia e a Fisiologia dos escolares, cujos trabalhos eram orientados segundo a inspiração da moderna Escola Bio-tipológica italiana. (BRUNO, 1936, p. 76).

Nessa secção, foram organizadas, pelo método de Viola ${ }^{8}, 5.400$ fichas completas de escolares do sexo masculino. Esse trabalho, era considerado

8 Giacinto Viola era membro da escola italiana de biotipologia e, apoiando-se em dados morfológicos, propunha um padrão classificatório com base na proporção numérica de medidas antropométricas: os normotipos, com simetria entre troncos, membros e abdômen; os braquitipos, com tronco maior que membros e abdômen maior que tórax; e os longitipos, apresentando membros maiores que tronco e tórax maior que abdômen $\mathrm{O}$ corpo era, então, concebido a partir de dois sistemas: o da "vida vegetativa", compreendendo as vísceras contidas no tronco, e o da "vida de relação", correspondendo aos membros. Viola também sugeria outra classificação, a partir de três grupos: os normoesplânquinicos, os megaloesplânquinicos e os microesplânquinicos. O termo 'esplânquinico' (ou esplâncnico) referia-se às proporções da região abdominal, com suas variações normais, 'megalo' (acima) e 'micro' (abaixo). (VIMIEIRO-GOMES, 2012, p. 709).

\begin{tabular}{|l|l|l|l|l|r|}
\hline Hist. Educ. (Online) & Porto Alegre & v. 22 & n. 54 & jan./abr. 2018 & p. 246-262
\end{tabular}


[...] o mais importante que já se realizou no Brasil sobre o assunto, permitiu o levantamento dos biotipos de brancos, pretos e mulatos, de 6 a 14 anos, e da curva de crescimento da criança do nordeste brasileiro, segundo o grupo etnologico. (BRUNO, 1936, p. 76).

Sobre esses dados e a determinação do coeficiente da nutrição nas várias idades, organizaram-se turmas homogêneas de escolares, para as praticas da educação física, medida indispensável para a regularidade e a eficiencia dos exercícios ginásticos.

Andrade Lima Junior e Luiz Ignacio ${ }^{9}$, os médicos responsáveis pela seção de Morfo-fisiologia do Departamento de Educação publicaram nos Archivos do Serviço de Antropologia e Medicina Escolar, para o ano de 1936, os resultados de suas pesquisas sobre o biótipo do escolar em Pernambuco. Segundo os médicos, o trabalho de coleta foi iniciado desde 1935 seguindo a orientação da Escola constitucionalista italiana. Os médicos dispunham para realizar o procedimento de 19 medidas carecidas para a determinação do morfotipo, além das medidas de diâmetros transvessos trocanteriano, acromial e cefálico, sagital cefálico, peso e altura de pé. Para realizar a análise previamente estabeleceram a mensuração somente de crianças masculinas afim de obter o maior rendimento no número das fichas colhidas.4.085, colhidas entre os escolares do Recife. Alunos de colégios particulares, escolas federais, instituições de caridade, escolas públicas, grupos escolares constituíam os elementos que tínhamos armazenado.

Tendo em vista a heterogeneidade dos escolares do ponto de vista racial como preocupação antecipada, os filhos de estrangeiros foram excluídos do processo (254 fichas foram descartadas). Ainda, sob o ponto de vista racial, o material foi colocado dentro dos grupos ditados por Roquette-Pinto: leucodermo (2.123), faiodermo (1.565) e melanodermo (os médicos informam que em face ao numero reduzido de crianças pretas foi necessário juntar os dois grupos etnicos, leucodermo e melanodermo, ou seja, pretos e mulatos).

Em suas pesquisas, os referidos médicos tinham como finalidade estabelecer as medidas basicas para a classificação do morfotipo da criança do nordeste, ressaltando a todo instante "a diferença acentuada do mulato em face do branco. Sempre as medidas do faiodermo mais curtas, mais estreitas que as do leucodermo". (LIMA JUNIOR; IGNACIO, 1936, p. 83). Assim, sob o ponto de vista etnico, os médicos afirmaram que o material agrupado era tanto quanto possivel homogeneo, e tambem no que se referia a indagação dos antepassados dos escolares,

[...] razão porque não apresentavam maior numero de crianças na organização dos calculos. [...] talvez nesse tempo atingindo o numero desejado de fichas, provinientes de grupos escolares localizados em zonas de aspecto social homogeneo. (LIMA JUNIOR; IGNACIO, 1936, p. 85).

De posse de 3.688 fichas, os autotres afirmavam que, talvez tivessem em mãos o maior número de fichas existente no gênero em todo o Brasil. Procederam agrupando pela idade cronológica, considerando como limites para cada ano, seis meses contados nos dois sentidos. mesmo admitindo que talvez fosse criticavel, esse agrupamento, no entanto, era uma norma homogênea, usada no trabalho e continuaria até que outra mais razoável se

\footnotetext{
9 Biotipologistas, membros da Escola de Educação Física do Exército no Rio de Janeiro que se ocuparam com pesquisas sobre a morfologia do homem do nordeste analisando soldados da Brigada Militar de Pernambuco em 1939. (ALBUQUERQUE JR., 1997, p. 97).
} 
apresentasse ou posteriormente pudessem dizer alguma coisa sobre os periodos de crescimento descritos por Pende ${ }^{10}$.

Luiz Ignacio e Andrade Lima Junior também foram responsáveis pela avaliação do estado nutricional dos escolares do Recife, no ano de 1938. Para tanto, foram utilizados diferentes fórmulas ou índices, entre os quais destacamos $O$ índice ponderal. Para se calcular o referido índice considerou-se o peso e a altura dos nossos escolares masculinos para estabelecer uma comparação cuidadosa com outras estatísticas que se conhecia na época. Em torno destes dois valores, se procurou compreender as relações entre o desenvolvimento somático e a nutrição. Foi desta maneira criado o Índice Ponderal, cuja formula é representada por

$$
1003 \frac{\text { peso }}{\text { altura }}
$$

Os referidos médicos relataram que o material analisado era composto de fichas com 72 medidas executadas e o índice ponderal devidamente calculado entre estudantes pernambucanos e paulistas. Assim, índice ponderal foi o seguinte:

Tabela 01 - Índice ponderal entre leucodermos e faiodermos.

\begin{tabular}{c|c|c}
\hline Idade & Leucodermos (brancos) & Faiodermos (negros) \\
\hline 7 & 230 & 236 \\
\hline 8 & 232 & 232 \\
\hline 9 & 231 & 232 \\
\hline 10 & 228 & 229 \\
\hline 11 & 227 & 228 \\
\hline 12 & 228 & 229 \\
\hline 13 & 225 & 227 \\
\hline
\end{tabular}

Fonte: LIMA JUNIOR; IGNACIO, 1938, p. 116.

Segundo os médicos, nos leucodermos (brancos) a maioria se recrutava entre os mais abastados, enquanto os faiodermos (negros) eram constituídos na sua percentagem mais alta pelos de classes mais pobres. Ainda, em relação a esses dados, os médicos informavam que

E bem verdade que a divisão etnológica não coincide exatamente com a separação social de classe rica e classe pobre. Porém num grupo e noutro a percentagem maior é, na nossa terra, evidentemente distinta.

O nosso achado se bem que menos evidente que os dos pesquisadores espanhóis, deixa entrever. Contudo, uma disposição aproximada daquelas diferenças.

\footnotetext{
10 O médico italiano Nicola Pende (1880-1970) é considerado o pai da biotipologia. Propunha uma associação entre características constitucionais e aspectos endocrinológicos, em que as secreções internas, de base genética, manifestar-se-iam por meio dos fenótipos, denotando as características individuais. (VIMIEIROGOMES, 2012, p. 712).
} 
O Índice Ponderal dos faiodermos sempre ligeiramente maior, nunca menor que os leucodermos. A explicação deste acontecimento não nos parece em nada esclarecida. (LIMA JUNIOR; IGNACIO, 1938, p. 116, grifos meus).

Portanto, os próprios médicos não sabiam por que os dados em relação a negros (faiodermos) e brancos (leucodermos) eram diferentes. Por isso, afirmam que continuaram pesquisando o Índice Ponderal ao lado de outros valores que melhor esclarecessem aquela situação, afim de que, quando na posse de melhor conhecimento da expressão dinâmica do estado fisio-morfológico, pudessem entender os fenômenos acima relatados. "Talvez com a estatística mais crescida surja esta compreensão, hoje, da nossa parte, ainda impossível." (LIMA JUNIOR; IGNACIO, 1938, p. 116).

Por fim, no processo de medições antropométricas entre os escolares pernambucanos verificamos que houve a racialização dos resultados para 0 estabelecimento do biótipo do escolar, procurando fornecer as bases científicas (antropométricas e higiênicas) para a constituição de turmas homogêneas intelectual e fisicamente. Contudo, os próprios médicos tinham certeza da impossibilidade de compreender as diferenças entre os grupos étnicos estudados para homogeneizar as classes como se pretendia.

\section{Algumas considerações}

As pesquisas que os médicos pernambucanos realizaram, tomando como sujeitos os alunos das escolas primárias seguiam a orientação da Escola Constitucionalista italiana. Nesse processo se utilizaram da educação física de orientação predominantemente higienista que se propagava a partir de discursos que levantavam a bandeira da eugenia.

Vale ressaltar que a eugenia brasileira diferenciou-se da europeia e da norteamericana, porque não defendia a eliminação dos supostos degenerados (através da esterilização ou mesmo extermínio), mas previa um melhoramento da raça e sua transformação em uma "raça" que refletisse o biótipo do brasileiro. Para garantir o melhoramento da raça brasileira, a ordem médica foi a de limpar a população das doenças epidêmicas que tanto se propagaram no século XIX, passando no século XX a se constituir um imperativo a ser combatido, enquanto a norma era obedecer à política higienista que foi sistematicamente implementada na organização escolar. Nesse contexto, a educação física assumiu um papel importante no cenário nacional e local oferecendo mecanismos para a promoção da saúde e garantindo o futuro da raça.

No espaço pernambucano, mais especificamente nas escolas primárias, a antropometria foi utilizada com o intuito de estabelecer o biotipo do escolar que frequentava tais escolas. Para tanto, o fator racial era levado em consideração e a classificação adotada era a de Edgard Roquette-Pinto: leucodermos (brancos), faiodermos (brancos $x$ negros), xantodermos (brancos $x$ índios) e melanodermos (negros). Assim, mesmo que os resultados dos testes estabelecessem comparações entre crianças brancas e negras em Pernambuco, não era possível explicar cientificamente as diferenças entre os referidos grupos étnicos. 


\section{Referências}

ALBUQUERQUE JUNIOR, Durval Muniz de. Breve, lento, mas compensador: a construção do sujeito nordestino no discurso sócio-antropológico e biotipológico da década de trinta. Afro-Ásia, Salvador, v. 19, n. 20, p. 95-107, 1997. Disponível em: <http://www.afroasia.ufba.br/pdf/afroasia_n19_20_p95.pdf >. Acesso em: 01 jun. 2013.

BRUNO, Aníbal. Serviço de antropologia e medicina escolar. In: PERNAMBUCO. Departamento de Educação. Archivos do Serviço de Antropologia e Medicina Escolar. Recife, 1936. p. 73-79.

CAMPOS, Gil de; MACEDO, Armando. Contribuição à antropometria do escolar recifense. Revista Medica de Pernambuco, Recife, ano 4, n. 3, p. 125-131, março 1934.

CHARTIER, Roger. A História Cultural: entre práticas e representações. Tradução de Maria Manuela Galhardo. Rio de Janeiro: Bertrand Brasil, 1990.

GONDRA, José Gonçalves. Medicina, higiene e educação escolar. In: LOPES, Eliane Marta Teixeira; FARIA FILHO, Luciano Mendes; VEIGA, Cynthia Greive (Orgs.). 500 anos de educação no Brasil. Belo Horizonte, MG: Autêntica, 2003. p. 519-550.

GOMES, José Oliveira. Educação física nas escolas públicas de Pernambuco. In: Boletim de educação. Departamento de Educação, Pernambuco, Brasil. v. 5, 1935. p. 18-38.

GHIRALDELLI JUNIOR, P. Educação Física Progressista - A Pedagogia crítico-social dos conteúdos e a Educação Física Brasileira. 3 ed. São Paulo: Editora Loyola, 1994.

KAERCHER, Gládis Elise Pereira da Silva. 0 mundo na caixa: gênero e raça no Programa Nacional Biblioteca da Escola - 1999. 2005. Tese (Doutorado) - Universidade Federal do Rio Grande do Sul - UFRGS, Faculdade de Educação, Programa de PósGraduação em Educação, Porto Alegre/RS, 2005.

. Pedagogias da racialização ou dos modos como se aprende a ter raça e/ou cor. In: BUJES, Maria Isabel Edelweiss; BONIN, lara Tatiana (Orgs.). Pedagogias sem fronteiras. Canoas, RS: ULBRA, 2010. p. 85-91.

LIMA JUNIOR, Andrade; IGNACIO, Luiz. O biótipo do escolar em Pernambuco. Departamento de educação de Pernambuco. Arquivos do serviço de antropologia e medicina escolar, Recife, p. 79-89, 1936.

. O índice ponderal. Revista Medica de Pernambuco, Recife, ano 11, n. 4, p. 111116, maio 1938.

MIRANDA, Waldemir. A pratica anthropometrica como preenche, neste particular, a ficha de educação physica (Para as monitoras de educação physica). Diretoria da Hygiene. Recife, Imprensa Oficial, 1931.

Relatório apresentado ao Inventor Federal no estado em 29 de dezembro de 1930. Diretoria da Hygiene, Recife, Imprensa Oficial, p. 1-6, 1930.

PERNAMBUCO. Departamento de Educação. Morfo-fisiologia. Recife, 1936.

Diretoria técnica da educação. Introdução. Boletim da Directoria Tecnica, Recife, ano I, n. I, p. 5-6, 1931.

Estado de. Secretaria de Estado dos Negocios da Justiça e da Instrução Pública. Anuario do Ensino do Estado de Pernambuco anno de 1923. Officinas Graphicas da Petinenciaria do Recife, 1923.

SOUZA, Vanderlei Sabastião. "As leis da eugenia" na antropologia de Edgard RoquettePinto. In: LIMA, Nísia Trindade; SÁ, Dominichi Miranda (Orgs.). Antropologia Brasiliana: ciência e educação na obra de Edgard Roquette-Pinto. Belo Horizonte: Ed. da UFMG, Rio 
de Janeiro: Ed. Fiocruz, 2008. p. 213-244.

SCHWARCZ, Lília Moritz. O espetáculo das raças: cientistas, instituições e questão racial no Brasil (1870-1930). São Paulo: Companhia das Letras, 1993.

SELLARO, Lêda Rejane Accioly. Educação e modernidade em Pernambuco: inovações no ensino público (1920-1937). Recife, PE: Universitária da UFPE, 2009.

STEPAN, Nancy Leys. A hora da Eugenia: Raça, gênero e nação na América Latina. Rio de Janeiro, RJ: FIOCRUZ, 2005. (Coleção História e Saúde).

VAGO, Mauro Tarcísio. Cultura escolar cultivo de corpos: Educação Physica e Gymnastica como práticas constitutivas dos corpos de crianças no ensino público primário de Belo Horizonte (1906-1920). Bragança Paulista: EDUSF, 2002.

VIMIEIRO-GOMES, Ana Carolina. A emergência da biotipologia no Brasil: medir e classificar a morfologia, a fisiologia e o temperamento do brasileiro na década de 1930. Boletim do Museu Paraense Emílio Goeldi, Ciências Humanas, v. 7, n. 3, p. 705-719, set./dez. 2012.

ADLENE SILVA ARANTES é professora Adjunta da Universidade de Pernambuco - UPE, Campus Mata Norte.

Endereço: Av. Ministro Marcos Freire, 410 - Bairro Novo - 55819-740 - Carpina/PE - Brasil. E-mail: adlene.arantes@hotmail.com

Recebido em 04 de setembro de 2016.

Aceito em 01 de novembro de 2017. 